\title{
The apple 14-3-3 protein MdGRF11 interacts with the BTB protein MdBT2 to regulate nitrate deficiency-induced anthocyanin accumulation
}

\author{
Yi-Ran Ren ${ }^{1}$, Qiang Zhao ${ }^{2}$, Yu-Ying Yang ${ }^{1}$, Tian-En Zhang ${ }^{1}$, Xiao-Fei Wang ${ }^{1}$, Chun-Xiang You ${ }^{1}$ and Yu-Jin Hao ${ }^{1}$
}

\begin{abstract}
Nitrogen is an important factor that affects plant anthocyanin accumulation. In apple, the nitrate-responsive BTB/TAZ protein MdBT2 negatively regulates anthocyanin biosynthesis. In this study, we found that MdBT2 undergoes posttranslational modifications in response to nitrate deficiency. Yeast two-hybrid, protein pull-down, and bimolecular fluorescence complementation (BiFC) assays showed that MdBT2 interacts with MdGRF11, a 14-3-3 protein; 14-3-3 proteins compose a family of highly conserved phosphopeptide-binding proteins involved in multiple physiological and biological processes. The interaction of MdGRF11 negatively regulated the stability of the MdBT2 protein via a $26 \mathrm{~S}$ proteasome-dependent pathway, which increased the abundance of MdMYB1 proteins to activate the expression of anthocyanin biosynthesis-related genes. Taken together, the results demonstrate the critical role of 14-3-3 proteins in the regulation of nitrate deficiency-induced anthocyanin accumulation. Our results provide a novel avenue to elucidate the mechanism underlying the induction of anthocyanin biosynthesis in response to nitrate deficiency.
\end{abstract}

\section{Introduction}

As sessile organisms, plants produce multiple secondary metabolites to cope with environmental stresses through sophisticated regulatory mechanisms ${ }^{1}$. Anthocyanins are a class of flavonoids ubiquitously distributed in plants. They are types of color-producing compounds in flowers, fruits, seeds, and leaves and provide plants with different colors-from orange-red to blue-purple ${ }^{2,3}$. For most plants, anthocyanin functions include resistance to low temperature, drought, and pathogen infections; protection against UV radiation and insect pests; attraction of pollinators; and facilitation of seed transmission ${ }^{4-7}$. Moreover, anthocyanins can benefit human nutrition and health due to their strong antioxidant properties and active oxygen-scavenging ability ${ }^{8}$.

Correspondence: Yu-Jin Hao (haoyujin@sdau.edu.cn)

'State Key Laboratory of Crop Biology, Shandong Collaborative Innovation Center for Fruit and Vegetable Production with High Quality and Efficiency, College of Horticulture Science and Engineering, Shandong Agricultural University, Tai-An, Shandong 271018, China

${ }^{2}$ Qingdao Agricultural University, Qingdao, Shandong 266109, China
It is well known that anthocyanins are derived from phenylpropanoids in the flavonoid biosynthesis pathway, in which a series of key enzymes and their encoding genes have been identified ${ }^{9}$. The expression of structural genes (UF3GT, ANS, DFR, F3H, CHI, and CHS) involved in anthocyanin biosynthesis is coordinately mediated by the MBW transcription complex, which is composed of three types of transcription factors (TFs): basic helix-loop-helix (bHLH), R2R3-MYB, and WD40-repeat proteins ${ }^{10}$. The MBW complex participates in the regulation of anthocyanin biosynthesis in various plant species ${ }^{11}$. In apple, the R2R3-MYB transcription factor MdMYB1 positively regulates anthocyanin biosynthesis by directly binding to the MdANS gene promoter ${ }^{12}$. The bHLH transcription factor MdbHLH3 promotes anthocyanin accumulation by activating the expression of $M d D F R$ and $M d U F G T^{13}$. In Arabidopsis, coexpression of the MYB TF AtPAP1 with the bHLH TFs AtTT8, AtGL3, or AtEGL3 can stimulate AtDFR promoter activity ${ }^{14}$.

Anthocyanin biosynthesis and accumulation are affected by endogenous signals such as phytohormones and

\section{(c) The Author(s) 2021}

(c) (i) Open Access This article is licensed under a Creative Commons Attribution 4.0 International License, which permits use, sharing, adaptation, distribution and reproduction cc) in any medium or format, as long as you give appropriate credit to the original author(s) and the source, provide a link to the Creative Commons license, and indicate if changes were made. The images or other third party material in this article are included in the article's Creative Commons license, unless indicated otherwise in a credit line to the material. If material is not included in the article's Creative Commons license and your intended use is not permitted by statutory regulation or exceeds the permitted use, you will need to obtain permission directly from the copyright holder. To view a copy of this license, visit http://creativecommons.org/licenses/by/4.0/. 
sugar as well as by multiple environmental stimuli, including drought, low temperature, UV irradiation, intense light, wounding, and nutrient deficiency ${ }^{15,16}$. Nitrogen $(\mathrm{N})$ is not only a necessary macronutrient for plant growth but also a key environmental factor that affects plant anthocyanin accumulation ${ }^{17-19}$. Nitrate deficiency induces the expression of bHLH and MYB TFs and represses the expression of zinc finger DNA-binding TFs LBD37, 38, and 39 to promote anthocyanin biosynthesis in Arabidopsis ${ }^{20,21}$. Overexpression of LBD37, 38 , or 39 downregulates the expression of $P A P 1$ and $P A P 2$, thereby inhibiting anthocyanin accumulation ${ }^{21}$. The RING-type E3 ubiquitin ligase NLA is involved in the induction of anthocyanin accumulation as an adaptative mechanisms to $\mathrm{N}$ limitation $^{22,23}$. Furthermore, DELLA proteins have also been identified to be involved in nitrate deficiency-induced anthocyanin biosynthesis ${ }^{24}$.

Recently, the nitrate-responsive protein MdBT2 was identified to participate in the nitrate-mediated anthocyanin biosynthesis pathway ${ }^{25}$. BT2, a member of the BTB/TAZ family, has been identified as a central gene in the nitrogen-use efficiency (NUE) network ${ }^{26,27}$. The nitrate-responsive genes $N L P 6$ and $N L P 7$ transcriptionally activate $B T 2$ to mediate the nitrate response ${ }^{28}$. The apple and Arabidopsis genomes encode five BTB/TAZ proteins, all of which have a C-terminal calmodulin-binding domain, a central TAZ domain, and an N-terminal BTB domain $^{29,30}$. In Arabidopsis, BT2 participates in multiple biological processes, including the regulation of gametophyte development and telomerase activity, as well as responses to light signals, hormones, stress, sugar, and nutrient status ${ }^{31-33}$. In apple, MdBT2 can interact with multiple types of substrate proteins to participate in different signaling pathways. For example, MdBT2 interacts with MdbHLH104, MdbHLH93, and MdMYB23 to negatively regulate $\mathrm{Fe}$ homeostasis, leaf senescence, and cold stress ${ }^{30,34,35}$.

Under adequate nitrate conditions, the expression of $M d B T 2$ is noticeably upregulated; in this case, MdBT2 mediates the ubiquitination and degradation of MdMYB1, thereby inhibiting anthocyanin accumulation $^{25}$. However, the molecular mechanism underlying how MdBT2 is regulated in nitrate-deficiency conditions remains unclear. Posttranslational modification is a crucial regulatory mechanism through which plants regulate protein expression in response to multiple environmental stresses. Wounding, UV-B, high light, and drought induce MdBT2 ubiquitination ${ }^{36-39}$. Moreover, BT2 is predicted to be a potential target gene of two SnRK1 kinases, KIN10 and KIN11, based on microarray data ${ }^{40}$. In this study, we found that nitrate deficiency induced MdBT2 degradation via the $26 \mathrm{~S}$ proteasome-dependent pathway. To further explore the underlying molecular mechanism, the MdBT2-interacting 14-3-3 protein
MdGRF11 was identified by the $\mathrm{Y} 2 \mathrm{H}$ method as a positive regulator of anthocyanin biosynthesis. MdGRF11 promoted the ubiquitination and degradation of the MdBT2 protein, which provided new insights for determining how anthocyanins accumulate under nitrate-deficiency conditions.

\section{Materials and methods \\ Plant materials and treatments}

Tissue cultures of apple GL-3, the seedlings of which were derived from open-pollinated Royal Gala (Malus $\times$ domestica cv. Royal Gala), were used as wild-type (WT) plants in this study. GL-3 tissue-cultured plantlets were grown on Murashige and Skoog (MS) media supplemented with $0.1 \mathrm{mg} / \mathrm{L} \mathrm{GA}_{3}, 0.2 \mathrm{mg} / \mathrm{L} \mathrm{NAA}$, and $0.3 \mathrm{mg} / \mathrm{L}$ 6-BA under a $16 \mathrm{~h} \mathrm{light} / 8 \mathrm{~h}$ dark photoperiod at $24^{\circ} \mathrm{C}$ and subcultured every four weeks. The Orin apple calli used for genetic transformation were grown on MS media consisting of $1.5 \mathrm{mg} / \mathrm{L} \mathrm{2,4-D}$ and $0.4 \mathrm{mg} / \mathrm{L} 6-\mathrm{BA}$ at normal temperature in darkness and subcultured at two-week intervals. Bagged apple fruits were harvested from Starkrimson apple trees at 120 days after full bloom (DAFB) for viral vector-mediated transient injection assays.

Arabidopsis ecotype Columbia (Col-0) was used for genetic transformation and phenotypic analysis. After being surface-sterilized and stratified for 3 days at $4{ }^{\circ} \mathrm{C}$, Arabidopsis seeds were sown on $1 / 2$-strength MS media under an 8/16-h dark/light photoperiod at $21^{\circ} \mathrm{C}$ for 3 to 5 days and then treated with different concentrations of nitrate for determination of their anthocyanin contents. grf9 (SALK_020026) mutants were obtained from the Arabidopsis Biological Resource Center (ABRC) mutant bank. The leaves of one-month-old Nicotiana benthamiana were used for bimolecular fluorescence complementation (BiFC) assays.

To detect the response of MdBT2 and MdGRF11 to nitrate deficiency, four-week-old apple (Malus domestica Rehd.) plantlets were treated with nitrogen-depleted Hoagland nutrient solution consisting of $5 \mathrm{mM} \mathrm{KCl}$ or $5 \mathrm{mM} \mathrm{KNO}_{3}$ for 3 days. Subsequently, the samples were used for qRT-PCR analysis.

For the phenotypic analysis of anthocyanin accumulation, the young shoots of four-week-old apple tissue culture GL-3 plantlets and two-week-old apple calli were transferred to the corresponding media deprived of nitrogen but consisting of either $5 \mathrm{mM} \mathrm{KCl}$ (nitrate deficiency) or $5 \mathrm{mM} \mathrm{KNO}_{3}$ (sufficient nitrate) under constant light for 7-10 days. The samples were subsequently harvested for expression analysis and measurement of anthocyanin contents.

\section{Vector construction and genetic transformation}

The full-length CDSs of MdBT2 and MdGRF11 were inserted into a pCXSN-MYC vector to generate the $35 \mathrm{~S}:$ : 
MdBT2-OX and 35 S::MYC-MdGRF11 overexpression vectors. An antisense suppression expression vector $35 \mathrm{~S}:$ : $M d B T 2-A n t i$ was generated by cloning the specific fragment of MdBT2 into a pCXSN vector. The $2000 \mathrm{bp}$ promoter fragment of MdGRF11 was cloned into a pCAMBIA1391-GUS vector, yielding a $\operatorname{Pro}_{M d G R F 11}:: G U S$ recombinant construct. The resultant vectors $M d B T 2-$

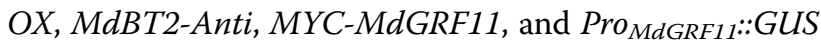
were subsequently genetically transformed into Orin apple calli via the Agrobacterium-mediated transformation method ${ }^{13}$. The primers used for vector construction are listed in Supplementary Table 1.

MdGRF11-OX and MdGRF11-Anti transgenic calli and MdGRF11 transgenic Arabidopsis were obtained as described previously ${ }^{41}$. Similarly, MdBT2-GFP transgenic calli were obtained as described previously ${ }^{30} . M d B T 2-O X$ and MdBT2-Anti transgenic apple plants were generated during our previous study ${ }^{35}$.

\section{Viral vector-mediated transient expression in apple skins and leaves}

The viral vectors $\mathrm{pIR}$ and TRV were used for transient injection in apple ${ }^{42,43}$. The full-length cDNAs of $M d G R F 11$ and $M d B T 2$ were cloned into a pIR vector to generate pIR-MdGRF11 and pIR-MdBT2 overexpression viral vectors. Fragments of $M d G R F 11$ and $M d B T 2$ were inserted into a tobacco rattle virus (TRV) vector to generate the TRV-MdGRF11 and TRV-MdBT2 suppression viral vectors. Moreover, the suppression viral vectors and an empty TRV vector were transformed into A. tumefaciens strain LBA4404. The recombinant plasmids or the A. tumefaciens solutions were subsequently injected into fresh-bagged apple fruit peels and apple leaves. The auxiliary vectors IL-60-BS and TRV1 were used for all sense or antisense coinjections, respectively. Fruit and leaf injection assays were performed as previously described $^{44,45}$. pIR and TRV empty vectors were used as controls.

The injected apples were kept in darkness at room temperature overnight and subsequently exposed to continuous white light at $21^{\circ} \mathrm{C}$ for $4-6$ days for coloration. The injected apple leaves were placed in $5 \mathrm{mM} \mathrm{KCl-}$ treated media under constant light at $21^{\circ} \mathrm{C}$ for $5 \mathrm{~d}$.

\section{Gene expression analysis}

Total RNA of apple calli, leaves, and fruit peels was extracted with an RNAplant Extraction Kit (CWBIO, Beijing, China), and cDNA was synthesized from one to five micrograms of RNA using a PrimeScript RT reagent kit (Takara, Dalian, China). qRT-PCR was performed with Ultra SYBR Mixture (CWBIO) in conjunction with an ABI 7500 Real-Time PCR System (Applied Biosystems) as described previously ${ }^{46}$. The relative gene expression level was calculated with the $2^{-\Delta \Delta \mathrm{CT}}(\mathrm{Ct})$ method. The $18 \mathrm{~s}$ gene was used as an internal reference. All samples were analyzed as three biological replicates. Sequences of the primers used for gene expression are listed in Supplementary Table 1.

\section{Protein extraction and Western blot analysis}

Apple calli or plantlets were ground into powder in liquid nitrogen and immediately immersed in protein extraction buffer [100 mM NaCl, $0.5 \mathrm{mM}$ EDTA, $20 \mathrm{mM}$ Tris- $\mathrm{HCl}$ (pH 7.5), $0.5 \mathrm{mM}$ PMSF, $0.5 \%$ Nonidet P-40 and $0.5 \%$ protease inhibitor] for $15 \mathrm{~min}$ on ice. The mixture was then centrifuged at $12,000 \mathrm{rpm}$ for $15 \mathrm{~min}$ at $4{ }^{\circ} \mathrm{C}$. The total protein supernatant was collected and separated on a $10 \%$ SDS-PAGE gel, transferred to a polyvinylidene fluoride (PVDF) membrane (Roche, IN, USA), and probed with anti-GFP antibody (Abmart, Shanghai, China). Western blotting assays were conducted as previously described $^{30}$. ACTIN served as a protein loading control.

\section{$\mathrm{Y} 2 \mathrm{H}$ screening and assays}

To screen the proteins that interact with MdBT2, the full-length cDNA of $M d B T 2$ was fused to the binding domain of the pGBT9 vector as bait (BD-MdBT2). The apple cDNA library was generated from apple skin and constructed by Oebiotech Company. $\mathrm{Y} 2 \mathrm{H}$ screening was conducted according to the Yeast Transformation System 2 manufacturer's instructions (Clontech, Shanghai, China), and the positive clones were determined by sequencing.

For the $\mathrm{Y} 2 \mathrm{H}$ assays, the coding sequences of $A t B T s$ and $M d B T s$ and the truncated sequences of $M d B T 2$ were cloned into a pGBT9 bait vector, while the full-length CDSs of MdGRFs and AtGRFs were inserted into a pGAD424 prey vector. The recombinant constructs were then cotransformed into yeast strain $\mathrm{Y} 2 \mathrm{H}$ Gold as described in the manufacturer's instructions (Clontech). The transformed yeast cells were cultured on SD/-TrpLeu (-T/-L) and SD/-Trp-Leu-His-Ade (-T/-L/-H/-A) media supplemented with 5-bromo-4-chloro-3-indolyl $\alpha$ $\mathrm{D}$-galactopyranoside $(\mathrm{X}-\alpha$-gal) for selection.

\section{Pull-down assays}

The full-length cDNA of $M d B T 2$ was inserted into a PGEX-4T-1 vector for glutathione S-transferase (GST) tag fusion, and the coding sequence of MdGRF11 was cloned into a PET-32a vector for $\mathrm{His}_{6}$ tag fusion. Both recombinant vectors were transformed into Escherichia coli BL21 for the expression of GST-MdBT2 and HisMdRGL3a proteins via $0.1 \mathrm{mM}$ isopropyl $\beta$-D-1- thiogalactopyranoside (IPTG) induction, respectively. Subsequently, the protein mixtures containing equal quantities of GST-MdBT2 and His-MdRGL3a proteins were eluted using a Pierce GST Spin Purification Kit (Thermo Fisher Scientific, MA, USA). GST protein acted as a negative 
control. The eluted solution was then subjected to immunoblot analysis with anti-HIS and anti-GST antibodies (Abmart).

\section{BiFC assays}

pSPYNE-35S, pSPYCE-35S, and the 35 S:p19 cotransformation vector were used for BiFC assays as described previously ${ }^{47}$. The full-length cDNAs of $M d B T 2$ and MdGRF11 were inserted into PSPYNE-35S and PSPYCE$35 \mathrm{~S}$, which contain DNA sequences encoding the $\mathrm{N}$ - or C-terminal halves of YFP $\left(\mathrm{YFP}^{\mathrm{N}}\right.$ or $\left.\mathrm{YFP}^{\mathrm{C}}\right)$, respectively. The recombinant constructs MdBT2-YFP ${ }^{\mathrm{N}}$ and MdGRF11-YFP ${ }^{C}$ were subsequently introduced into Agrobacterium strain GV3101. The Agrobacterium strains containing different combinations and the Agrobacterium carrying the p19 silencing plasmid were incubated and cosuspended in infiltration buffer consisting of $10 \mathrm{mM}$ $\mathrm{MgCl}_{2}, 10 \mathrm{mM}$ MES, and $0.2 \mathrm{mM}$ acetosyringone to a final concentration of which the OD600 was 0.5 . YFP ${ }^{\mathrm{N}}$ and $\mathrm{YFP}^{\mathrm{C}}$ empty vectors were used as negative controls. Subsequently, $N$. benthamiana leaf epidermal cells were infiltrated and incubated at $24^{\circ} \mathrm{C}$ for 2 days. YFP fluorescence was detected using a Zeiss LSM 510 Meta highresolution laser-scanning confocal microscope (Jena, Germany).

\section{Cell-free and in vivo protein degradation assays}

For cell-free degradation assays, total proteins of apple calli or plantlets were extracted with protein degradation buffer comprising $25 \mathrm{mM}$ Tris- $\mathrm{HCl}$ (pH 7.5), $10 \mathrm{mM}$ $\mathrm{MgCl}_{2}, 5 \mathrm{mM}$ DTT, $10 \mathrm{mM} \mathrm{NaCl}, 4 \mathrm{mM} \mathrm{PMSF}$, and $10 \mathrm{mM}$ ATP, as previously described ${ }^{46}$. Afterward, $100 \mathrm{ng}$ of Escherichia coli BL21-induced GST-MdBT2, HISMdMYB1, and HIS-MdGRF11 recombinant proteins and equal amounts of the above total proteins $(500 \mu \mathrm{g})$ were incubated together at $22^{\circ} \mathrm{C}$ for different time periods. The samples were then subjected to immunoblot analysis with anti-GST or anti-His antibodies. For the proteasome inhibitor MG132 treatment, total protein extracts were pretreated with $50 \mu \mathrm{M}$ MG132 for 30 min before being incubated together with recombinant proteins.

In nitrate-mediated GST-MdBT2 protein stability assays, four-week-old apple plantlets (Malus domestica Rehd.) were pretreated with nitrogen-depleted Hoagland nutrient solution consisting of either $5 \mathrm{mM} \mathrm{KCl}$ or $5 \mathrm{mM}$ $\mathrm{KNO}_{3}$ for 3 days, after which the total protein extracts from these plantlets and recombinant GST-MdBT2 proteins were incubated together for the indicated times. The proteins were detected using anti-GST antibodies.

For in vivo degradation assays, two-week-old MdBT2GFP and MYC-MdGRF11+MdBT2-GFP calli were treated with $250 \mu \mathrm{M}$ cycloheximide (CHX) with or without $50 \mu \mathrm{M}$ MG132 in the dark. Total proteins were extracted at the indicated times with the abovementioned protein extraction buffer and then analyzed by immunoblotting using an anti-GFP antibody. Quantification of the protein levels was performed by Quantity One software (Bio-Rad, CA, USA), and ACTIN was used as a control.

\section{Ubiquitination assays}

For in vivo ubiquitination assays, MYC-MdBT2 and $M d G R F 11-G F P+M Y C-M d B T 2$ calli were pretreated with $50 \mu \mathrm{M}$ MG132 for $6 \mathrm{~h}$ in the dark before extraction. The MYC-MdBT2 proteins were immunoprecipitated with an anti-MYC antibody (Abmart) according to the method for the Pierce Classic Protein A IP Kit (Thermo Fisher Scientific). The resultant proteins were subjected to immunoblot analysis with anti-MYC and anti-ubiquitin antibodies (Sigma-Aldrich, MO, USA).

\section{Determination of anthocyanin contents}

Total anthocyanins in apple tissue culture GL-3 plantlets, leaves, fruit peels, and calli and in Arabidopsis were extracted via the methanol- $\mathrm{HCl}$ method. The plant materials were incubated in anthocyanin extraction solution $[1 \%(\mathrm{v} / \mathrm{v})$ methanol-HCl] in darkness at room temperature for $24 \mathrm{~h}$. The absorbance values of the extract samples were determined at 530, 620, and $650 \mathrm{~nm}$ with a spectrophotometer (SOPTOP, Shanghai, China). The relative anthocyanin content was calculated according to previously described methods ${ }^{48}$.

\section{GUS staining and activity analysis}

For histochemical staining, $\operatorname{Pro}_{\text {MdGRF11 }}:$ GUS calli treated with $5 \mathrm{mM} \mathrm{KCl}$ or $5 \mathrm{mM} \mathrm{KNO}_{3}$ were incubated in GUS staining buffer (1 mM 5-bromo-4-chloro-3-indolyl$\beta$-glucuronide, $10 \mathrm{mM}$ EDTA, $0.1 \%$ Triton X-100, $0.05 \mathrm{mM}$ ferricyanide, $0.05 \mathrm{mM}$ ferrocyanide, $20 \%$ methanol and $0.1 \mathrm{M}$ sodium phosphate buffer, $\mathrm{pH} 7.0$ ) at $37^{\circ} \mathrm{C}$ for $12 \mathrm{~h}$.

GUS activity analysis was carried out according to previously described methods ${ }^{13}$.

\section{Accession numbers}

Sequence data of the following genes (and their accession numbers) in this article can be found in the GDR: MdBT1 (MDP0000151000), MdBT2 (MDP0000643281), MdBT3.1 (MDP0000296225), MdBT3.2 (MDP0000187156), MdBT4 (MDP0000215415), MdGRF11 (MD10G1280300), MdGRF4 (MD05G1301400), MdGRF6 (MD07G1096000), and MdGRF18 (MD17G1074900). Similarly, sequence data of the following genes (and their accession numbers) in this article can be found in the Arabidopsis Genome Initiative database: AtBT1 (At5g63160), AtBT2 (At3g48360), AtBT3 (At1g05690), AtBT4 (At5g67480), AtBT5 (At4g37610), AtGRF1 (At4g09000), AtGRF2 (At1g78300), AtGRF3 (At5g38480), AtGRF4 (At1g35160), AtGRF5 (At5g16050), AtGRF6 (At5g10450), AtGRF7 (At3g02520), AtGRF8 
(At5g65430), AtGRF9 (At2g42590), AtGRF10 (At1g22300), AtGRF11 (At1g34760), AtGRF12 (At1g26480), and AtGRF13 (At1g78220).

\section{Results}

Nitrate deficiency negatively regulates MdBT2 expression

Nitrate deficiency induces anthocyanin accumulation in apple $^{49}$. The young shoots of apple tissue culture GL-3 plantlets treated with $\mathrm{KCl}$ (nitrate deficiency) accumulated higher levels of anthocyanin content than the young shoots of $\mathrm{KNO}_{3}$-treated (sufficient nitrate) GL-3 plantlets did (Fig. 1a, b). MdBT2 has been shown to be a negative regulator of anthocyanin accumulation ${ }^{25}$. Here, we specifically detected the effect of MdBT2 on anthocyanin biosynthesis under nitrate-deficiency conditions. After
$\mathrm{KCl}$ treatment, compared with the wild-type (WT) controls, the $M d B T 2$ overexpression transgenic apple lines (MdBT2-OX1, OX5, and OX7) accumulated less anthocyanin, while suppression lines (MdBT2-Anti13 and Anti23) accumulated more anthocyanin (Supplementary Fig. 1a-c). Furthermore, the expression levels of genes related to anthocyanin biosynthesis, including $M d D F R$, MdANS, and MdUF3GT, were markedly downregulated in the $M d B T 2$ overexpression transgenic apple lines (Supplementary Fig. 1d-f).

To further study the molecular mechanism of MdBT2 in response to nitrate deficiency regulating anthocyanin biosynthesis, the transcriptional and posttranslational levels of MdBT2 were measured in response to nitrate deficiency. qRT-PCR assays showed that the transcript

\section{(a)}

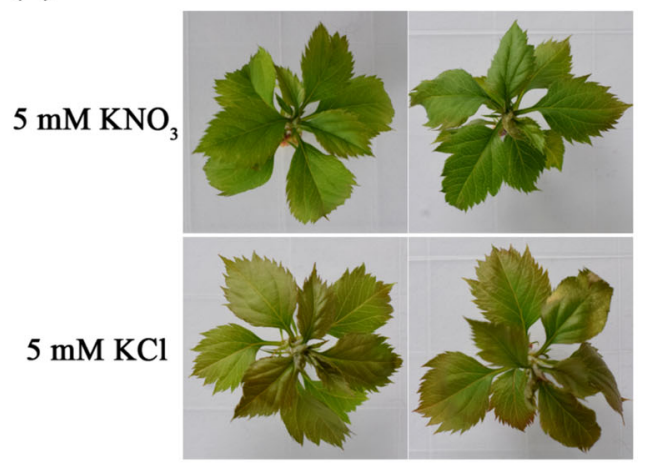

(c)

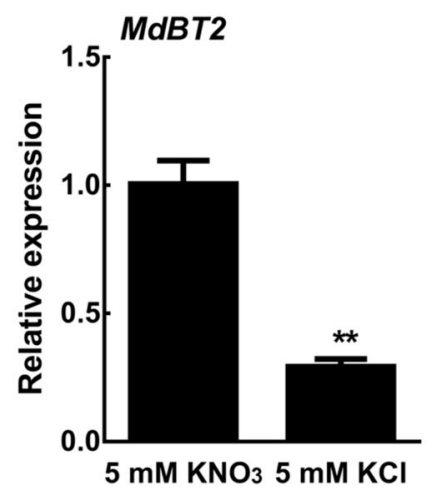

(b)

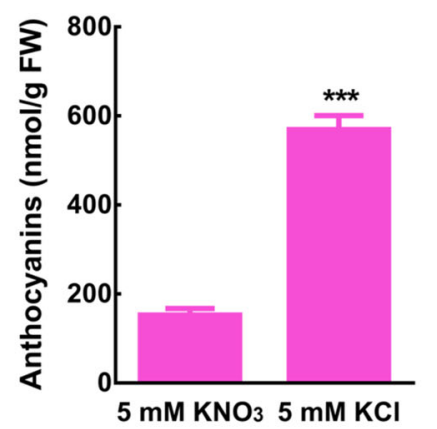

(d)

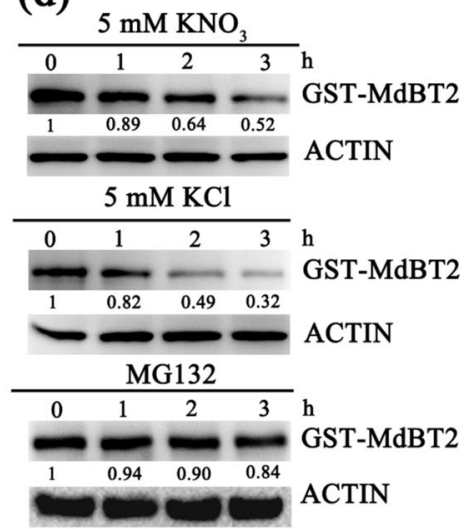

Fig. 1 Nitrate deficiency negatively regulates MdBT2 expression. a Anthocyanin pigmentation phenotype of four-week-old apple tissue culture GL-3 plantlets treated with $5 \mathrm{mM} \mathrm{KCl}$ (nitrate deficiency) or $5 \mathrm{mM} \mathrm{KNO}_{3}$ (sufficient nitrate) under constant light for 10 d. b Anthocyanin content in apple tissue culture $\mathrm{GL}-3$ plantlets treated with $5 \mathrm{mM} \mathrm{KCl}$ or $5 \mathrm{mM} \mathrm{KNO}_{3}$. The error bars indicate the SDs of three biological replicates, with at least 6 plantlets per replicate. The asterisks indicate significant differences $\left({ }^{* *} P<0.001\right)$ based on Student's $t$ test. $\mathbf{c}$ Expression analysis of MdBT2 in response to nitrate deficiency. Four-week-old apple plantlets were treated with nitrogen-depleted Hoagland nutrient solution supplemented with $5 \mathrm{mM} \mathrm{KCl}$ or $5 \mathrm{mM} \mathrm{KNO}_{3}$ for 3 days. The $18 \mathrm{~s}$ gene was used as an internal reference. The error bars indicate the SDs of three independent biological replicates. The asterisks indicate significant differences (**P<0.01) based on Student's $t$ test. $\mathbf{d}$ Cell-free degradation assays of MdBT2 in response to nitrate treatment. Four-week-old apple plantlets were treated with $5 \mathrm{mM} \mathrm{KCl}$ or $5 \mathrm{mM} \mathrm{KNO} 3$ for 3 days, and then the total protein extracts from these plantlets and recombinant GST-MdBT2 proteins were incubated together for the indicated times. For the proteasome inhibitor MG132 treatment, total protein samples extracted from $5 \mathrm{mM} \mathrm{KCl}$-treated apple plantlets were pretreated with $50 \mu \mathrm{M} \mathrm{MG} 132$ for $0.5 \mathrm{~h}$ before sampling began. Anti-GST antibody was used for immunoblotting. ACTIN was used as loading control. The protein levels at $0 \mathrm{~h}$ were set to 1 
level of $M d B T 2$ was noticeably downregulated after treatment with $\mathrm{KCl}$ (Fig. 1c). In addition, a cell-free protein degradation assay was also conducted to detect the abundance of the MdBT2 protein. The immunoblot results showed that, compared with $\mathrm{KNO}_{3}$ treatment, $\mathrm{KCl}$ treatment accelerated GST-MdBT2 protein degradation (Fig. 1d). Moreover, the degradation of MdBT2 was significantly inhibited in the presence of the proteasome inhibitor MG132 (Fig. 1d), indicating that the degradation of MdBT2 was dependent on the $26 \mathrm{~S}$ proteasome pathway. Taken together, these findings indicated that nitrate deficiency suppressed the expression of MdBT2 at the transcriptional and posttranslational levels.

\section{MdGRF11 interacts with MdBT2}

A Y2H screening assay was carried out to identify the potential proteins mediating the stability of MdBT2 in response to nitrate deficiency. The CDS of $M d B T 2$ was integrated into the binding domain of a pGBT9 vector as bait (BD-MdBT2) to screen its interacting partners in the apple cDNA library. After screening, a positive colony that contained a cDNA fragment encoding the 14-3-3 protein MD10G1280300, named MdGRF11, was isolated $^{41}$. To verify the interaction, the ORF sequence of MdGRF11 was fused to a pGAD424 vector as prey (ADMdGRF11) and cotransformed into yeast together with BD-MdBT2 for a Y2H assay. MdGRF11 interacted with MdBT2 (Fig. 2a). Furthermore, the interactions of MdGRF11 with the other four MdBTs were also investigated. However, MdGRF11 interacted only with MdBT2 and not with MdBT1, MdBT3.1, MdBT3.2, or MdBT4 (Fig. 2a). Previous studies have indicated that MdGRF11 can form a heterodimer together with MdGRF4, MdGRF6, and MdGRF18 ${ }^{41}$. The Y2H assay showed that MdBT2 also interacted with MdGRF4, MdGRF6, and MdGRF18 (Supplementary Fig. 2a). The Arabidopsis AtBT2 protein is homologous to $\mathrm{MdBT}^{25}$, and the $\mathrm{Y} 2 \mathrm{H}$ assay showed that AtBT2 also interacted with MdGRF11, AtGRF8, AtGRF9, and AtGRF10 proteins (Supplementary Fig. 2b, c). To determine which domain of MdBT2 was required for interacting with MdGRF11, MdBT2 was divided into its $\mathrm{C}$-terminal calmodulin-binding domain, TAZ domain, and N-terminal BTB domain. As shown in Fig. $2 b$, both the BTB and TAZ domains are required for MdBT2 interaction with MdGRF11 (Fig. 2b).

The in vitro interaction between MdBT2 and MdGRF11 was confirmed by a pull-down assay. The results showed that the His-MdGRF11 protein was pulled down only by GST-MdBT2 and not by the GST control (Fig. 2c), demonstrating that MdGRF11 interacted with MdBT2 in vitro. In addition, a BiFC assay was carried out to further determine their interactions in vivo. MdGRF11 and MdBT2 were integrated into the C-terminal fragment or N-terminal fragment of YFP, yielding MdGRF11-YFP and MdBT2-YFP ${ }^{\mathrm{N}}$ constructs, respectively. As a result, a strong yellow fluorescent signal was detected in the nucleus of epidermal cells cotransformed together with MdGRF11-YFP ${ }^{\mathrm{C}}$ and MdBT2-YFP ${ }^{\mathrm{N}}$. In contrast, none of the fluorescent signals were observed in the control samples (Fig. 2d). These results indicated that MdGRF11 physically interacted with MdBT2.

\section{Nitrate deficiency positively regulates MdGRF11 expression}

14-3-3 phosphopeptide-binding proteins are highly conserved in cells of eukaryotes, including plants, animals, and yeast ${ }^{50}$. Protein sequence alignment showed that MdGRF11 and its orthologous protein AtGRF9 contained a conserved 14-3-3 domain (Fig. 3a). To explore the role of MdGRF11 in the response to nitrate deficiency, the expression levels of MdGRF11 in response to $\mathrm{KCl}$ and $\mathrm{KNO}_{3}$ were measured. The results showed that nitrate deficiency ( $\mathrm{KCl}$ treatment) significantly induced the expression of MdGRF11 (Fig. 3b). Furthermore, a GUS staining assay showed that the $\mathrm{KCl}$ treatment caused much higher GUS activity than did the $\mathrm{KNO}_{3}$ treatment in $\operatorname{Pro}_{\text {MdGRF11 }}:$ GUS transgenic calli, which was opposite the expression pattern of $M d B T 2$ (Fig. 3c, d). Taken together, these results indicated that MdGRF11 played a positive role in the response to nitrate deficiency.

\section{MdGRF11 promotes nitrate deficiency-induced anthocyanin accumulation}

Considering that MdGRF11 interacted with MdBT2 and participated in the response to nitrate deficiency, it was hypothesized that MdGRF11 is involved in nitratemediated anthocyanin accumulation. To prove this hypothesis, Orin apple calli (WT), MdGRF11 overexpression (MdGRF11-OX), and MdGRF11 suppression (MdGRF11-Anti) transgenic calli were used to detect anthocyanin accumulation. In MdGRF11-Anti transgenic calli, the expression levels of MdGRF4, MdGRF6, and MdGRF18 were also inhibited, possibly due to sequence similarity and functional redundancy (Supplementary Fig. 3a). After treatment for 7 days, three types of calli produced less anthocyanins in response to $\mathrm{KNO}_{3}$ than to $\mathrm{KCl}$ (Fig. 4a, b). Moreover, compared with the WT control calli, MdGRF11-OX transgenic calli noticeably accumulated more anthocyanins, and MdGRF11-Anti transgenic calli accumulated less anthocyanins, particularly in the media treated with $\mathrm{KCl}$ (Fig. 4a, b). In accordance with the anthocyanin phenotypes, the expression of the anthocyanin biosynthesisrelated genes $M d F 3 H, M d D F R, M d A N S$, and MdUF3GT was markedly upregulated in the MdGRF11-OX transgenic calli but suppressed in the MdGRF11-Anti transgenic calli (Fig. 4c-f). 
(a)

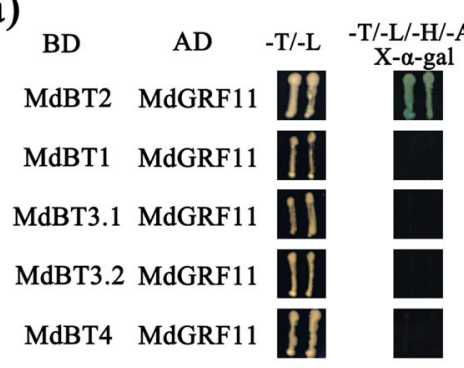

(c)

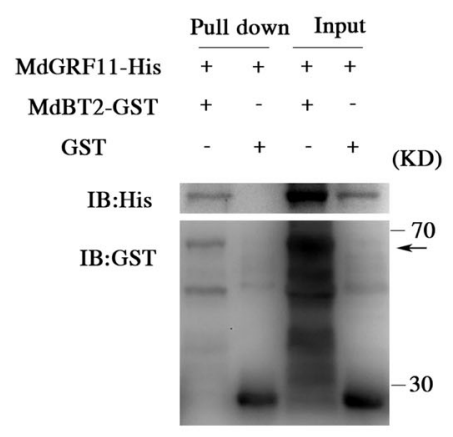

(b)

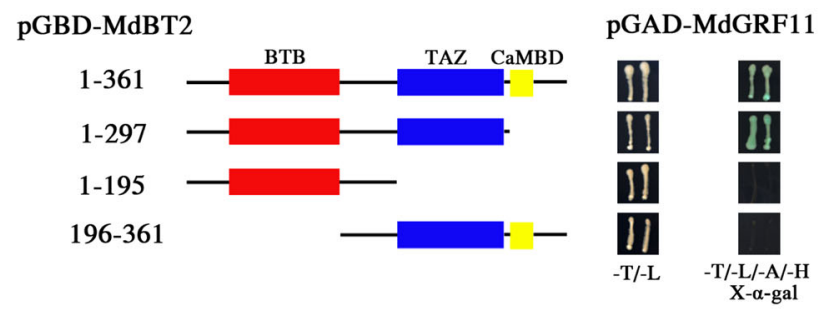

(d)

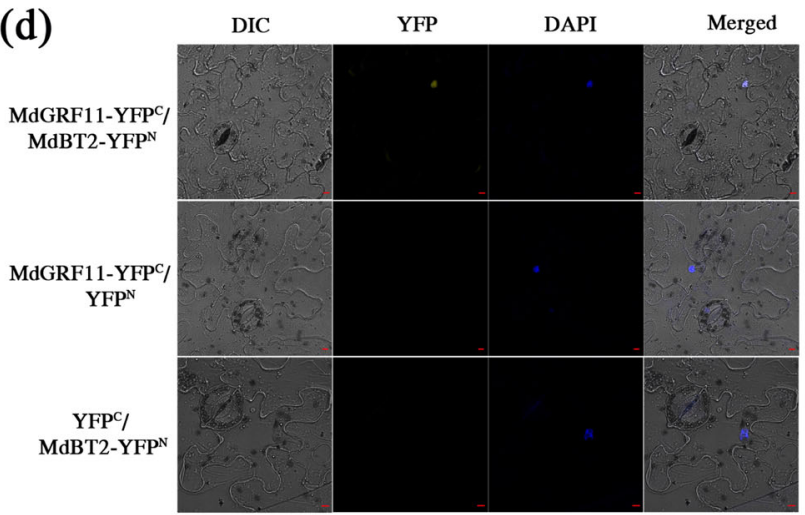

Fig. 2 MdGRF11 interacts with MdBT2 proteins. a Yeast two-hybrid assay to examine the interactions of MdGRF11 with MdBT1, MdBT2, MdBT3.1, MdBT3.2, and MdBT4. Yeast cells were grown on SD/-Trp-Leu (-T/-L) and SD/-Trp-Leu-His-Ade (-T/-L/-H/-A) media. X-a-gal was used to further confirm the positive interactions. $\mathbf{b}$ Y2H assay to determine the domain through which MdBT2 interacts with MdGRF11. c In vitro pull-down assay indicating the interaction of MdBT2 and MdGRF11. His-MdGRF11 proteins and GST-MdBT2 or GST fusion proteins were incubated together and then purified with a GST column. Immunoprecipitated proteins were detected with anti-HIS and anti-GST antibodies. IB immunoblotted. d Interaction between MdBT2 and MdGRF11 detected by a BiFC assay in transiently transformed N. benthamiana leaf epidermal cells. DAPI was used as a marker for the nucleus. YFP fluorescence was observed via confocal microscopy. Scale bars, $10 \mu \mathrm{m}$

MdGRF11 transgenic Arabidopsis was also generated to confirm the function of MdGRF11 in regulating anthocyanin accumulation. Nitrate treatment promoted root growth and inhibited anthocyanin accumulation in Arabidopsis (Supplementary Fig. 4). Overexpression of MdGRF11 also promoted nitrate deficiency-induced anthocyanin biosynthesis (Fig. 4g, h). However, the phenotype of the grf9 mutant did not differ from that of the control (Col-0) (Fig. 4g, h and Supplementary Fig. 3b), indicating that functional redundancy exists among GRF members. In conclusion, these data suggested that MdGRF11 acted as a positive regulator of anthocyanin accumulation induced by nitrate deficiency.

\section{MdGRF11 promotes the destabilization of MdBT2}

In animals, 14-3-3 proteins have been reported to mediate the stability of their target proteins by direct protein-protein interactions $^{51}$. To investigate the influence of the interaction between MdGRF11 and MdBT2 on the stability of MdBT2, a cell-free degradation experiment was conducted. Purified GST-MdBT2 proteins were added to total protein samples extracted from WT control, MdGRF11-OX, and MdGRF11-Anti transgenic calli. Western blot analysis demonstrated that GST-MdBT2 proteins degraded faster in MdGRF11-OX protein extracts than in the WT control extracts but much slower in MdGRF11-Anti protein extracts (Fig. 5a), suggesting that MdGRF11 contributed to the degradation of MdBT2 proteins. Furthermore, MdGRF11-mediated degradation of MdBT2 was noticeably inhibited in the presence of MG132 (Fig. 5a). Taken together, these results revealed that the degradation of MdBT2 was dependent on the $26 \mathrm{~S}$ proteasome pathway.

To further verify the influence of MdGRF11 on MdBT2 proteins in vivo, MYC-MdGRF11 was transformed into $M d B T 2-G F P$ transgenic calli to generate $M Y C$ $M d G R F 11+M d B T 2-G F P$ double transgenic calli (Supplementary Fig. 5a). The MdBT2-GFP and $M Y C$ $M d G R F 11+M d B T 2-G F P$ calli were then treated with the protein synthesis inhibitor cycloheximide ( $\mathrm{CHX})$ for different durations to examine the abundance of MdBT2. Western blotting assays showed that the degradation of MdBT2 was accelerated in the MYC-MdGRF11+ $M d B T 2-G F P$ calli compared with the MdBT2-GFP calli. However, MG132 notably inhibited the degradation of MdBT2 in the MYC-MdGRF11+MdBT2-GFP calli 


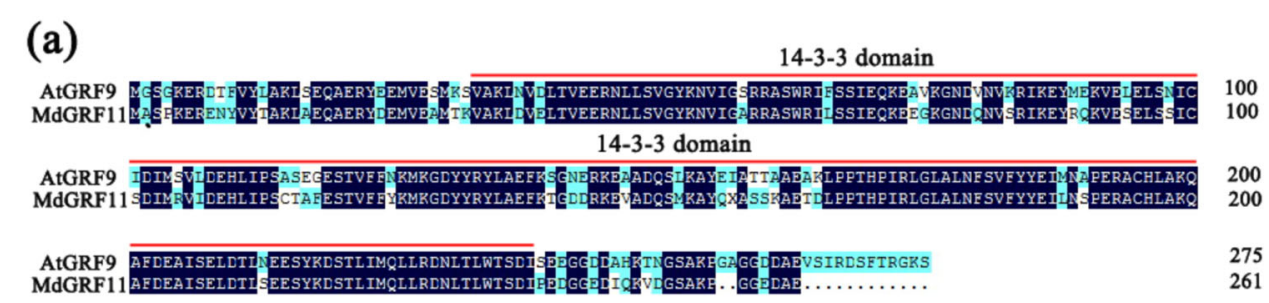

(b)

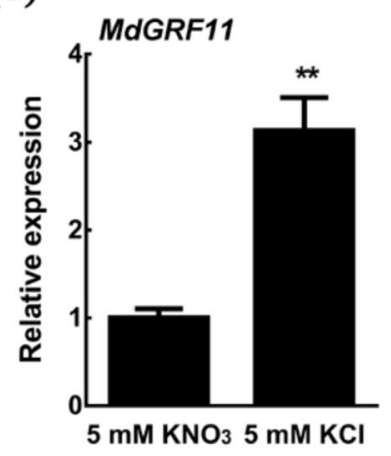

(c)

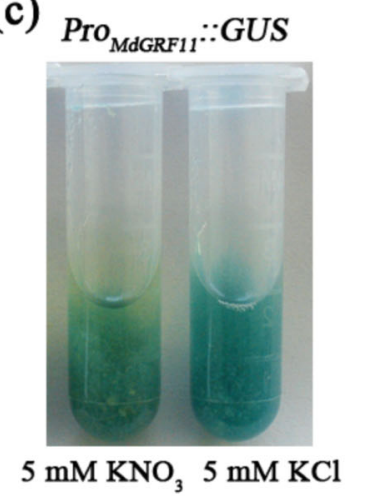

(d)

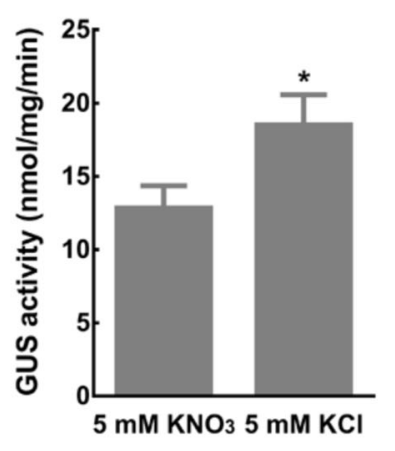

Fig. 3 Nitrate deficiency positively regulates MdGRF11 expression. a Protein sequence alignment of MdGRF11 and its orthologous protein AtGRF9. The red line represents the scope of the conserved 14-3-3 domain. $\mathbf{b}$ qRT-PCR analysis of the relative MdGRF11 expression level in response to nitrate deficiency. Four-week-old apple plantlets were treated with $5 \mathrm{mM} \mathrm{KCl}$ or $5 \mathrm{mM} \mathrm{KNO}_{3}$ for 3 days. The $18 \mathrm{~s}$ gene was used as an internal reference. c GUS staining images of Pro MdGRF17::GUS transgenic calli treated with $5 \mathrm{mM} \mathrm{KCl}$ or $5 \mathrm{mM} \mathrm{KNO}_{3}$ for $12 \mathrm{~h}$. d Quantitative analysis of GUS activity in $\mathbf{c}$. In $\mathbf{b}, \mathbf{d}$, the error bars indicate the SDs of three independent experiments. The asterisks indicate significant differences $\left({ }^{*} P<0.05\right.$; ${ }^{* *} P<$ 0.01) based on Student's $t$ test

(Fig. 5b), indicating that MdGRF11 negatively regulated MdBT2 protein stability via the $26 \mathrm{~S}$ proteasomedependent pathway.

To determine whether MdGRF11-mediated degradation of MdBT2 depended on the ubiquitin/proteasome pathway, MdBT2 proteins were immunoprecipitated from $M Y C-M d B T 2$ and $M d G R F 11-G F P+M Y C-M d B T 2$ calli with anti-MYC antibodies. The results indicated that $M d G R F 11-G F P+M Y C-M d B T 2$ calli generated more of the polyubiquitinated form MYC-MdBT2 than did the MYC-MdBT2 calli (Fig. 5c, d). Thus, MdGRF11 promoted the ubiquitination and subsequent degradation of the MdBT2 protein.

Generally, BTB proteins degrade their target proteins by combining with CULLIN3 to form the CULLIN-3 E3 (CUL3) ubiquitin ligase complex ${ }^{52}$. To confirm whether MdBT2 affected the protein stability of MdGRF11, protein degradation assays were conducted in vitro. The suppression vector $M d B T 2-A n t i$ and the overexpression vector $M d B T 2-O X$ were introduced into the apple calli (Supplementary Fig. 5b). The cell-free assays showed that there was no significant difference in the degradation rate of HIS-MdGRF11 among the WT control, $M d B T 2-O X$, and $M d B T 2-A n t i$ callus protein extracts (Supplementary Fig. 6). These data indicated that MdBT2 did not affect the stability of the MdGRF11 protein, indicating that the MdGRF11 14-3-3 protein was not a substrate of MdBT2.

\section{MdGRF11 negatively regulates MdBT2-mediated anthocyanin accumulation}

Considering that both MdGRF11 and MdBT2 are involved in nitrate deficiency-mediated anthocyanin accumulation and that MdGRF11 contributes to the degradation of MdBT2, it was reasonable to suspect that MdGRF11 influences MdBT2-mediated anthocyanin biosynthesis. Thus, MdGRF11-Anti and MdGRF11-OX constructs were introduced into $M d B T 2-O X$ calli (Supplementary Fig. 5c). The resultant $M d B T 2-O X$, $M d G R F 11-O X+M d B T 2-O X$, and MdGRF11-Anti+ $M d B T 2-O X$ transgenic calli were used to detect the anthocyanin accumulation in $\mathrm{KCl}$-treated media, while WT calli were used as a control. Overexpression of $M d B T 2$ noticeably decreased the anthocyanin accumulation. Additionally, overexpression of MdGRF11 partially suppressed, whereas suppression of $M d G R F 11$ promoted MdBT2-mediated anthocyanin accumulation (Fig. 6a, b). Expression analysis showed that the expression levels of the anthocyanin biosynthesis-related genes $M d F 3 H$, $M d D F R, M d A N S$, and MdUF3GT were markedly downregulated in $M d B T 2-O X$ calli, and this phenomenon could be altered by $M d G R F 11$ overexpression or suppression 

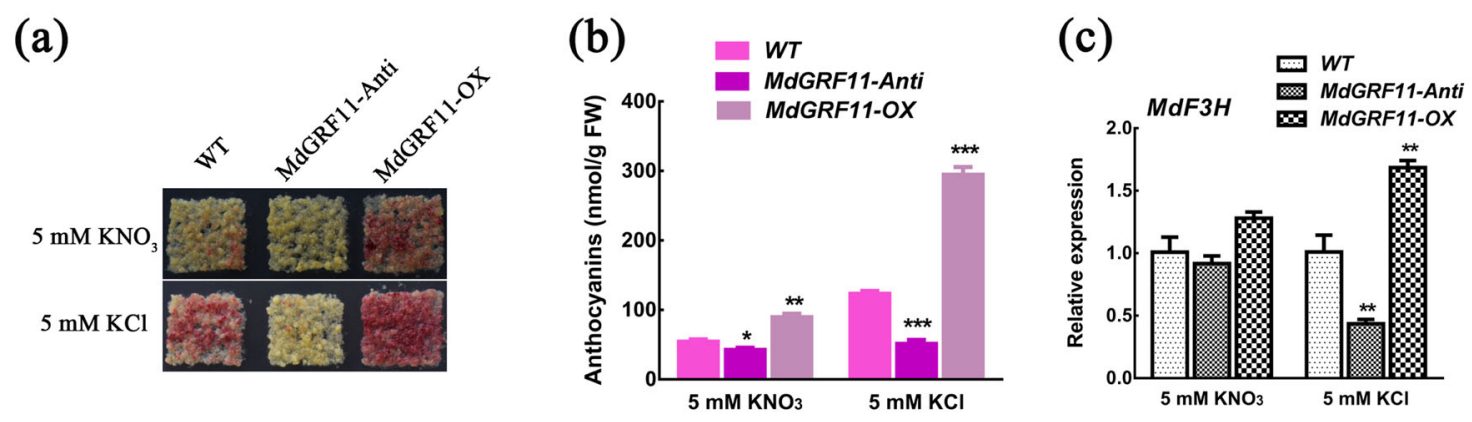

(d)
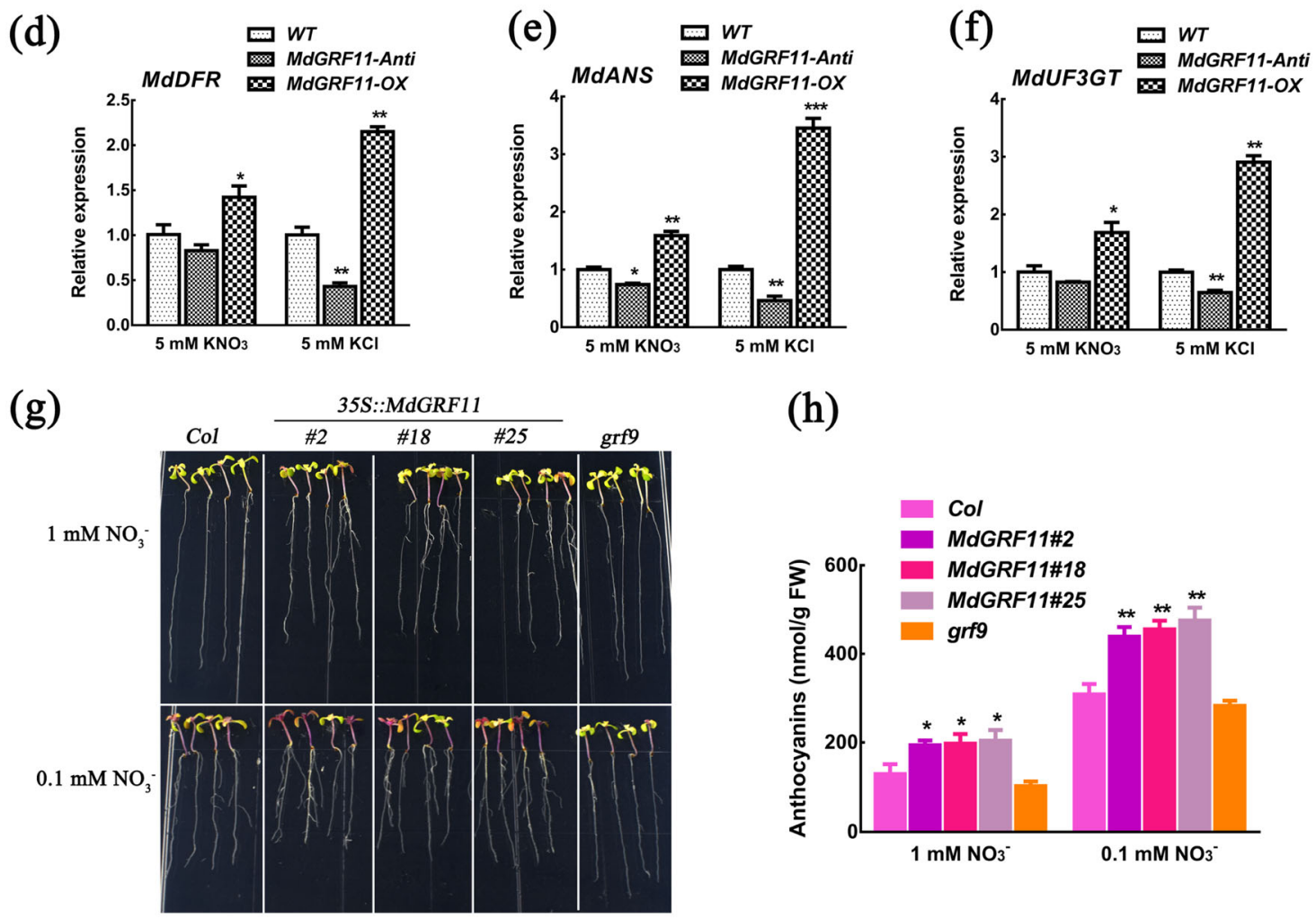

(h)

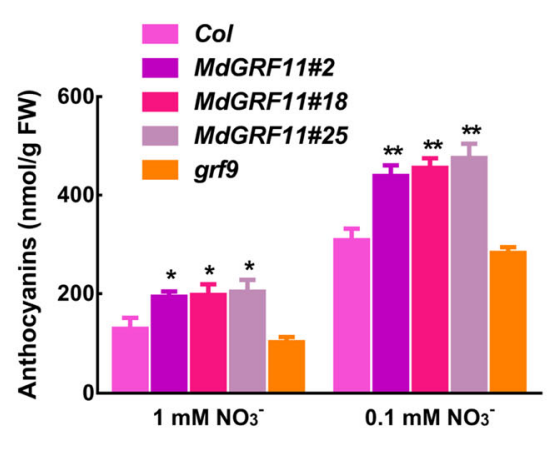

Fig. 4 MdGRF11 promotes nitrate deficiency-induced anthocyanin accumulation. a Callus coloration of two-week-old wild-type (WT), MdGRF11-OX, and MdGRF11-Anti transgenic calli treated with $5 \mathrm{mM} \mathrm{KCl}$ or $5 \mathrm{mM} \mathrm{KNO}_{3}$ for 7 days. b Anthocyanin contents in a. c-f Expression analysis via qRT-PCR of the anthocyanin biosynthesis-related genes MdF3H, MdDFR, MdANS, and MdUF3GT in the apple calli shown in $\mathbf{a}$. The 18s gene acted as an internal control. g Phenotypes of Col-0, grf9 mutant, and MdGRF11 transgenic Arabidopsis seedlings (35 S::MdGRF11\#2, \#18 and \#25) grown on media consisting of $0.1 \mathrm{mM} \mathrm{KNO}_{3}$ or $1 \mathrm{mM} \mathrm{KNO}_{3}$. $\mathbf{h}$ Anthocyanin contents in $\mathbf{g}$. In $\mathbf{b}-\mathbf{f}, \mathbf{h}$ the error bars indicate the SDs of three independent experiments, each of which included three technical replicates. The asterisks indicate significant differences $\left({ }^{*} P<0.5 ;{ }^{* *} P<0.01 ;{ }^{* * *} P<0.001\right)$ based on Student's $t$ test

(Fig. 6c). Taken together, these results demonstrated that MdGRF11 negatively regulated MdBT2-mediated anthocyanin biosynthesis in apple calli.

Previous studies have shown that MdBT2 inhibits anthocyanin accumulation by promoting MdMYB1 degradation ${ }^{25}$. Therefore, it was also hypothesized that MdGRF11 regulated MdBT2-mediated MdMYB1 protein stability to affect anthocyanin biosynthesis. The cell-free degradation assay showed that the degradation rate of HIS-MdMYB1 proteins was faster in protein extracts of
MdBT2-OX than in those the WT control. When MdGRF11 was suppressed in the background of MdBT2$O X$ calli, the degradation of HIS-MdMYB1 proteins was accelerated in the MdGRF11-Anti $+M d B T 2-O X$ protein extracts. However, overexpression of MdGRF11 nearly prevented MdBT2-induced HIS-MdMYB1 degradation in the MdGRF11-OX + MdBT2-OX protein extracts (Supplementary Fig. 7), suggesting that MdGRF11-regulated anthocyanin biosynthesis was at least partly dependent on the MdBT2-MdMYB1 regulatory module. 
(a)

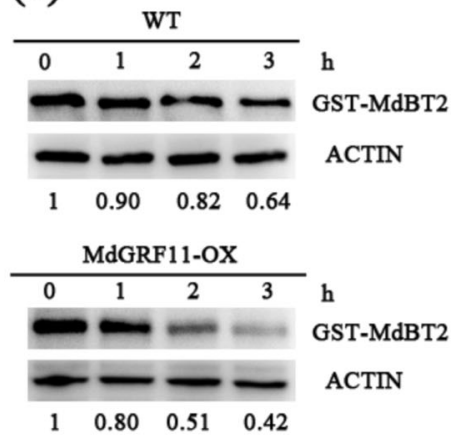

(c)

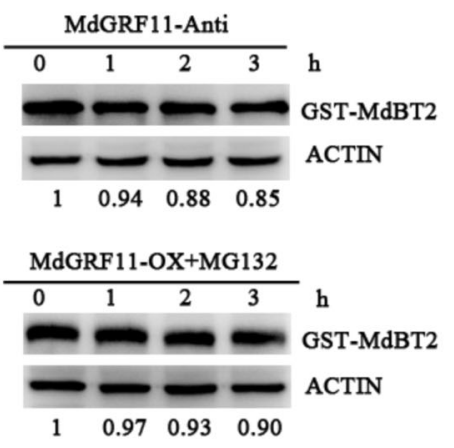

(d) (b)

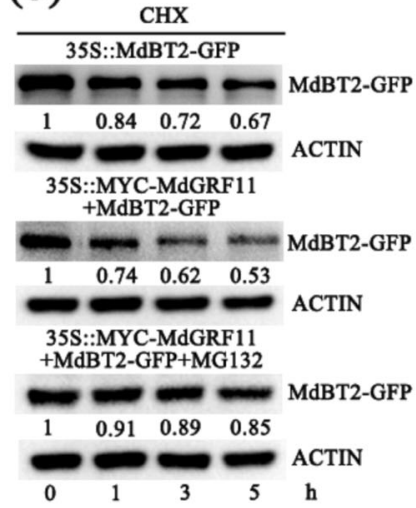

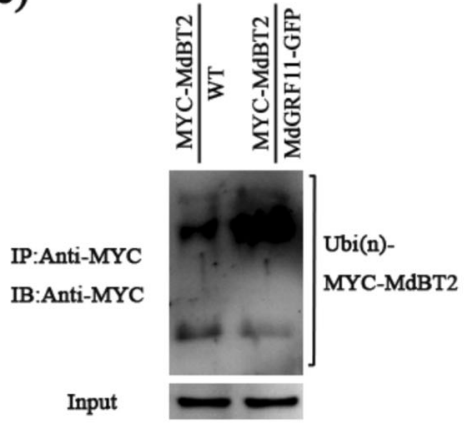

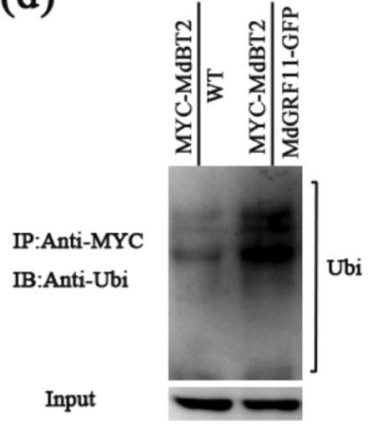

Fig. 5 MdGRF11 promotes the destabilization of MdBT2. a In vitro cell-free degradation assay in WT control, MdGRF11-OX, and MdGRF11-Anti transgenic apple calli. Equal quantities of recombinant GST-MdBT2 protein and total protein samples extracted from WT, MdGRF11-Anti, or MdGRF11OX apple calli treated with or without MG132 were incubated together at $22^{\circ} \mathrm{C}$ for the indicated period. Anti-GST antibody was used to detect GSTMdBT2 protein abundance. $\mathbf{b}$ In vivo MdBT2 protein degradation assay. The MdBT2-GFP protein abundances in two-week-old MdBT2-GFP and MYCMdGRF11 + MdBT2-GFP transgenic calli were detected with an anti-GFP antibody according to the indicated time after treatment with $250 \mu \mathrm{M}$ cycloheximide (CHX) with or without MG132 in the dark. ACTIN was used as a loading control. The protein levels at $0 \mathrm{~h}$ were set to $1 . \mathbf{c}$, $\mathbf{d}$ Ubiquitination of MdBT2 protein in MYC-MdBT2 and MdGRF11-GFP + MYC-MdBT2 transgenic calli. MYC-MdBT2 proteins were immunoprecipitated using the anti-MYC antibody from these two transgenic calli after pretreatment with $50 \mu \mathrm{M} \mathrm{MG132}$ in the dark for $6 \mathrm{~h}$. The immunoprecipitated proteins were detected with anti-MYC antibodies (c) and anti-ubiquitin antibodies (d). IB immunoblotted, IP immunoprecipitated

To explore the role of MdBT2 and MdGRF11 in apple peel coloration, viral vector-mediated transient injection assays were carried out in apple skins. qRT-PCR analysis showed that the transcript levels of $M d B T 2$ and MdGRF11 correspondingly increased or decreased in response to injection of apple skins (Supplementary Fig. 8). As a result, overexpression of $M d B T 2$ (pIRMdBT2) inhibited anthocyanin biosynthesis in apple skins around the infiltration sites, while overexpression of MdGRF11 (pIR-MdGRF11) promoted the biosynthesis compared with that of the controls. In addition, when pIR-MdGRF11 and pIR-MdBT2 were coinjected together, the anthocyanin accumulation was higher than that of pIR-MdBT2 alone but still lower than that of the pIR control (Fig. 6d, e). Coinjection of TRV-MdGRF11 and TRV-MdBT2 resulted in increased anthocyanin accumulation compared with that resulting from the TRV control, as did TRV-MdBT2 (Fig. 6g, h). Moreover, the trends of the relative expression levels of the structural genes MdF3H, MdDFR, MdANS, and MdUF3GT were similar to the trends of anthocyanin accumulation in the injected fruit peels (Fig. 6f, i).

The overexpression viral vector pIR-MdGRF11 and suppression viral vector TRV-MdGRF11 were subsequently used for transient infection of GL-3 apple leaves. The results indicated that MdGRF11 promoted anthocyanin accumulation in apple leaves (Supplementary Fig. 9a-c). Moreover, pIR-MdGRF11 and TRV-MdGRF11 were transiently infected into apple leaves of $M d B T 2$ overexpression transgenic apple lines (MdBT2-OX1, OX5, and OX7) and suppression lines (MdBT2-Anti13 and Anti23), with pIR and TRV empty vectors serving as controls. These results indicated that MdGRF11 inhibited MdBT2-mediated anthocyanin biosynthesis in apple leaves (Supplementary Fig. 9d-k), similar to the findings pertaining to the apple calli and apple fruits.

\section{Discussion}

Anthocyanin biosynthesis is regulated by various signal transduction pathways that integrate multiple hormone 


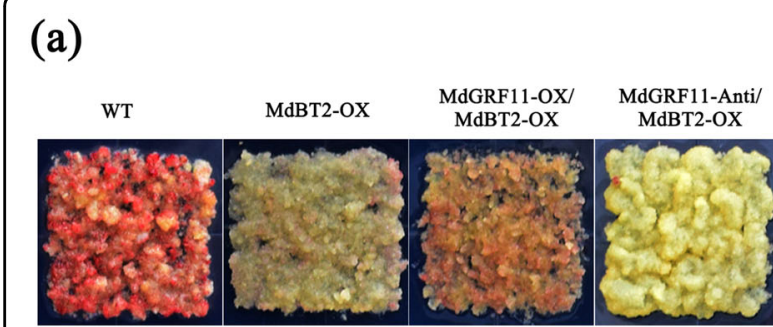

(d)

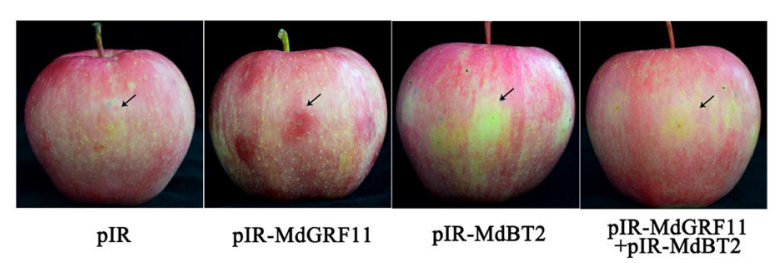

(g)

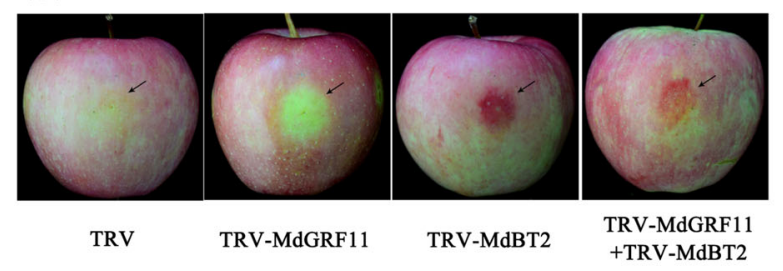

(b)

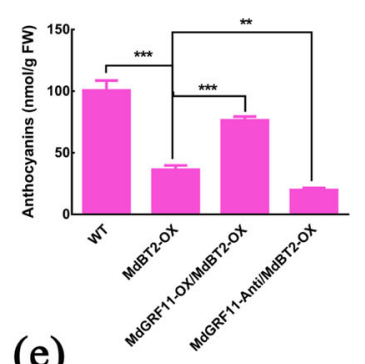

(e)
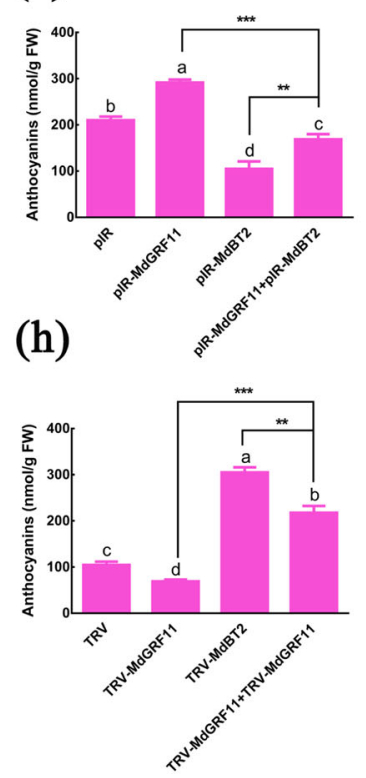

(c)

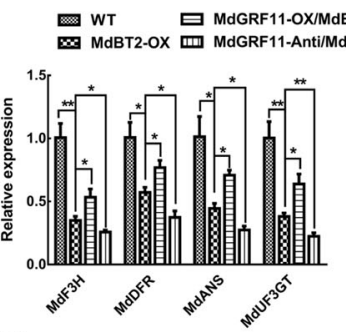

(f)

国 $\mathrm{plR}$ pIR-MdGRF11 口 pIR-MdBT2 四 pIR-MdGRF11+pIR-MdBT2

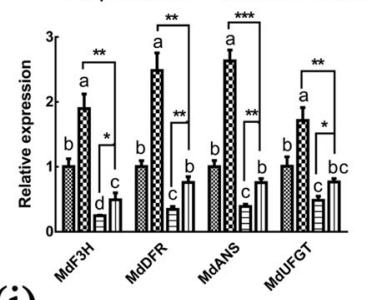

(i) TRV 1 TRV-MdGRF11
日RV-MdBT2 2 TRV-MdGRF11+TRV-MdBT2

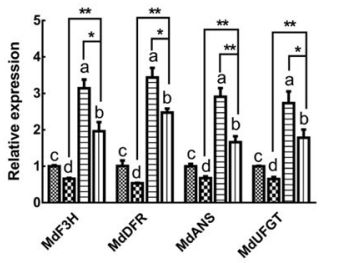

Fig. 6 MdGRF11 negatively regulates MdBT2-mediated anthocyanin accumulation. a Coloration of WT, MdBT2-OX, MdGRF11-OX + MdBT2-OX, and MdGRF11-Anti + MdBT2-OX transgenic calli treated with $5 \mathrm{mM} \mathrm{KCl}$ for 7 days. b Anthocyanin contents in the corresponding calli shown in a. c Relative expression levels of the anthocyanin biosynthesis-related genes MdF3H, MdDFR, MdANS, and MdUF3GT in the apple calli shown in a. The 18s gene acted as an internal control. $\mathbf{d}$ Coloration of apple fruit peels injected with plasmid mixtures (pIR-MdGRF11, pIR-MdBT2, and pIR-MdGRF11 + pIR-MdBT2). An empty pIR vector was used as control. e, f Anthocyanin contents (e) and relative expression levels of the anthocyanin biosynthesisrelated genes MdF3H, MdDFR, MdANS, and MdUF3GT (f) around the injection sites of the fruit peels shown in $\mathbf{d}$. The $18 \mathrm{~s}$ gene acted as an internal control. $\mathbf{g}$ Coloration of apple fruit peels injected with a mixed solution of Agrobacterium cells (TRV-MdGRF11, TRV-MdBT2, and TRV-MdGRF11+TRVMdBT2). An empty TRV vector was used as a control. $\mathbf{h}$, i Anthocyanin contents (h) and transcript levels of anthocyanin biosynthesis-related genes (i) around the injection sites of the fruit peels shown in $\mathbf{g}$. The $18 \mathrm{~s}$ gene acted as an internal control. In $\mathbf{b}, \mathbf{c}, \mathbf{e}, \mathbf{f}, \mathbf{h}, \mathbf{i}$, the error bars indicate the SDs of three independent experiments, each of which included three technical replicates. The different letters represent significant differences (LSD test, $P<$ 0.05). The asterisks indicate significant differences $\left({ }^{*} P<0.5 ;{ }^{*} P<0.01 ;{ }^{* *} P<0.001\right)$ based on Student's $t$ test

and environmental signals, such as nitrate $e^{9,15,16}$. Nitrate deficiency-induced anthocyanin biosynthesis has been reported in many species, including Arabidopsis and apple, and many proteins have been identified to participate in this process, including MYB, bHLH, LBD, and NLA proteins ${ }^{17,20,21,23}$. In apple, the nitrate-responsive protein MdBT2 degrades MdMYB1 proteins, which inhibit MdMYB1-induced anthocyanin accumulation under adequate nitrogen conditions ${ }^{25}$. However, the mechanisms underlying MdBT2-MdMYB1 pathway suppression under nitrate-deficiency conditions remain elusive. In this study, we found that the 14-3-3 protein MdGRF11 promotes the degradation of the MdBT2 protein, thereby enhancing the abundance of the MdMYB1 protein, which in turn induces anthocyanin accumulation in response to nitrate deficiency.

As a substrate adapter of Cullin-RING E3 ubiquitin ligase (CRL3), MdBT2 can modulate the stability of multiple proteins in response to environmental signals ${ }^{30,52}$. Recent studies have demonstrated that MdBT2 negatively regulates anthocyanin biosynthesis by modulating the abundance of the MdMYB1, MdBBX22, MdWRKY40, MdERF38, and MdTCP46 proteins in response to nitrate, UV-B, wounding, drought stress, and high light, respectively ${ }^{25,36-39}$. MdBT2 also undergoes ubiquitination in response to external environmental 
factors $^{36-39}$ (Fig. 1d). In mammalian cells, some E3 ligase components are ubiquitinated and degraded through the $26 \mathrm{~S}$ proteasome. For example, the F-box protein Atrogin1 is ubiquitinated and degraded through the p38 mitogenactivated protein kinase-dependent pathway ${ }^{53}$. Likewise, the anaphase-promoting complex promotes the degradation of the F-box protein S-phase kinase-associated protein 2 (Skp2) in the cell cycle phase G1 ${ }^{54}$. In Arabidopsis, interactions with 14-3-3 proteins may enhance the selfubiquitination activity of the F-box protein $\mathrm{FBS}^{55}$. Here, the 14-3-3 protein MdGRF11 was shown to interact with and promote the destabilization of the BTB protein MdBT2 (Figs. 2, 5). The number of identified gene families encoding E3 ligase components in plants has greatly increased, and the number of their related functions may increase. The regulation of BT2 protein stability may imply the function of scaffold proteins in bridging the gap between the response to environmental signals and the regulation of downstream target proteins, representing an increase in the complexity of the plant $26 \mathrm{~S}$ proteasome system.

14-3-3 proteins are highly conserved phosphopeptidebinding proteins that participate in multiple physiological and biological processes, including the stress response, primary metabolism, signal transduction, and membrane transport ${ }^{56,57}$. Recent studies have indicated that the 14-33 lambda (14-3-3 $\lambda$ ) protein regulates anthocyanin biosynthesis during drought stress ${ }^{58}$. In apple, a total of 20 14-3-3 genes have been identified to encode functional proteins ${ }^{41}$. Among them, the expression pattern of MdGRF11 was opposite that of MdBT2 in response to nitrate deficiency (Fig. 3b-d). Overexpression of MdGRF11 promoted nitrate deficiency-induced anthocyanin biosynthesis in transgenic calli and Arabidopsis (Fig. 4). Anthocyanin biosynthesis plays a vital role in the antioxidant defense mechanism to scavenge excess reactive oxygen species $(\mathrm{ROS})^{59}$. Therefore, anthocyanin accumulation in MdGRF11 overexpression transgenic lines may explain the role of MdGRF11 in positively regulating stress tolerance to some extent ${ }^{41}$. 14-3-3 proteins have high functional redundancy, which is a primary obstacle to studying the function of individual 14-3-3 isoforms ${ }^{57}$. Consistent with this, MdBT2 was found to interact with multiple 14-3-3 isoforms (Supplementary Fig. 2a), and the grf 9 mutant did not exhibit a significant difference in anthocyanin content compared with that of the control (Col-0) (Fig. 4g, h). However, MdGRF11-Anti transgenic calli, which repressed the expression of multiple 14-3-3 isoforms, accumulated markedly lower anthocyanin levels than did the WT control (Fig. 4a, b), suggesting that the redundancy of 14-3-3 proteins was at play in anthocyanin biosynthesis.

Generally, 14-3-3 proteins interact with target proteins and mediate their characteristics, such as protein activity, stability, subcellular localization, conformation, and affinity for other proteins $s^{50,51,57}$. In mammalian cells, 14-3-3 proteins promote the self-ubiquitination and degradation of the E3 ligases MURINE DOUBLE MINUTE2 (MDM2) and CONSTITUTIVE PHOTOMORPHOGENIC 1 (COP1), thus enhancing the stability of p53, a short-lived tumor suppressor protein $^{60,61}$. In Arabidopsis, 14-3-3 proteins have also been shown to positively regulate the stability of the type-2 1-aminocyclopropane-1-carboxylate synthase (ACS) protein. The regulation is partially caused by decreasing the abundance of $\mathrm{BTB}$ proteins ETHYLENE-OVERPRODUCER 1 (ETO1)/ETO1-LIKE (EOLs), which target type-2 ACS proteins for ubiquitination and degradation ${ }^{62}$. Here, we describe a similar mechanism in which the 14-3-3 protein MdGRF11 negatively regulated $\mathrm{BTB}$ protein MdBT2 stability in a $26 \mathrm{~S}$ proteasome-dependent pathway and thus increased the abundance of MdMYB1 proteins to promote anthocyanin biosynthesis under nitrate-deficiency conditions (Figs. 5, 6 and Supplementary Fig. 7).

Previous studies have demonstrated that the yeast F-box proteins Met30p, Grr1p, and Cdc4p are unstable and undergo ubiquitination and degradation via an autocatalytic mechanism within their own SCF complex, thereby ensuring that cells quickly adapt to extracellular signals and the progression of the cell cycle ${ }^{63}$. Furthermore, F-box proteins dimerize within the assembled SCF complex, which contributes to the stable binding of the F-box protein to its substrate and to its effective ubiquitination $^{64,65}$. The BTB proteins MEL-26 and Keap1 also dimerize, and this dimerization makes them subject to degradation $^{66,67}$. 14-3-3 proteins mainly exist in a homo-/ heterodimeric form, and they binds to target proteins through a phosphorylated serine/threonine, thereby exerting their regulatory function ${ }^{50,57}$. It was demonstrated that 14-3-3 proteins promote F-box protein Fbx4 dimerization following $\mathrm{Fbx} 4$ phosphorylation, thereby enhancing the E3 ligase activity of $\mathrm{SCF}^{\mathrm{Fbx} 468}$. It is thus possible that interaction with dimeric 14-3-3 proteins may promote the dimerization of CRL3, hence stimulating MdBT2 self-ubiquitination and degradation via the $26 \mathrm{~S}$ proteasome pathway. Moreover, phosphorylation of MdBT2 could generate a 14-3-3 binding site, though this has not been demonstrated in MdBT2 interactions. Furthermore, identification of the phosphorylation site of MdBT2 and the potential kinases involved would provide new insights into the mechanism underlying MdBT2 protein modifications in response to nitrate deficiency.

Previous studies have demonstrated that 14-3-3 proteins are central components in the plant signaling network for integrating various external and internal inputs $^{56}$. 14-3-3s mediate the stability of target proteins through direct interactions, and this action may be a universal mechanism for regulating signaling components 
in plants. Additionally, the regulation of E3 ligase component stability may play a vital role in plant signaling regulatory networks.

\section{Acknowledgements}

This work was financially supported by grants from the National Key R\&D Program of China (2018YFD1000200), National Natural Science Foundation of China (31772288, 31972378), and Science and Technology Program of Yunnan Province (2019ZG002-1-03).

\section{Author contributions}

Y.-J.H. and Y.-R.R. conceived and designed the research. Y.-R.R., Y.-Y.Y., and T.-E.Z. performed the experiments. Q.Z., X.-F.W., and C.-X.Y. provided technical assistance. Y.-J.H. and Y.-R.R. analyzed the data and wrote the manuscript.

\section{Conflict of interest}

The authors declare that they have no conflict of interest.

Supplementary Information accompanies this paper at (https://doi.org/ 10.1038/s41438-020-00457-z).

Received: 27 September 2020 Accepted: 16 November 2020 Published online: 01 February 2021

\section{References}

1. Bennett, R. N. \& Wallsgrove, R. M. Secondary metabolites in plant defence mechanisms. N. Phytol. 127, 617-633 (2010)

2. Springob, K., Nakajima, J., Yamazaki, M. \& Saito, K. Recent advances in the biosynthesis and accumulation of anthocyanins. Nat. Prod. Rep. 20, 288-303 (2003).

3. Lepiniec, L. et al. Genetics and biochemistry of seed flavonoids. Annu. Rev. Plant Biol. 57, 405-430 (2006).

4. Steyn, W., Wand, S., Holcroft, D. \& Jacobs, G. Anthocyanins in vegetative tissues: a proposed unified function in photoprotection. N. Phytol. 155, 349-361 (2002).

5. Shang, Y. et al. The molecular basis for venation patterning of pigmentation and its effect on pollinator attraction in flowers of Antirrhinum. N. Phytol. 189, 602-615 (2011)

6. Zhang, Y. et al. Anthocyanins double the shelf life of tomatoes by delaying overripening and reducing susceptibility to gray mold. Curr. Biol. 23 , 1094-1100 (2013).

7. Nakabayashi, R. et al. Enhancement of oxidative and drought tolerance in Arabidopsis by overaccumulation of antioxidant flavonoids. Plant J. 77, 367-379 (2014).

8. Butelli, E. et al. Enrichment of tomato fruit with health-promoting anthocyanins by expression of select transcription factors. Nat. Biotechnol. 26 1301-1308 (2008)

9. Jaakola, L. New insights into the regulation of anthocyanin biosynthesis in fruits. Trends Plant Sci. 18, 477-483 (2013).

10. Albert, N. W. et al. A conserved network of transcriptional activators and repressors regulates anthocyanin pigmentation in eudicots. Plant Cell 26, 962-980 (2014).

11. Ramsay, N. A. \& Glover, B. J. MYB-bHLH-WD40 protein complex and the evolution of cellular diversity. Trends Plant Sci. 10, 63-70 (2005).

12. Ban, $Y$. et al. Isolation and functional analysis of a MYB transcription factor gene that is a key regulator for the development of red coloration in apple skin. Plant Cell Physiol. 48, 958-970 (2007).

13. Xie, X. B. et al. The bHLH transcription factor MdbHLH3 promotes anthocyanin accumulation and fruit colouration in response to low temperature in apples. Plant Cell Environ. 35, 1884-1897 (2012).

14. Zimmermann, I. M., Heim, M. A., Weisshaar, B. \& Uhrig, J. F. Comprehensive identification of Arabidopsis thaliana MYB transcription factors interacting with R/B-like BHLH proteins. Plant J. 40, 22-34 (2004).

15. Guo, J., Han, W. \& Wang, M. Ultraviolet and environmental stresses involved in the induction and regulation of anthocyanin biosynthesis: a review. Afr. J. Biotechnol. 7, 4966-4972 (2008)

16. Das, P. K., Shin, D. H., Choi, S. B. \& Park, Y. I. Sugar-hormone cross-talk in anthocyanin biosynthesis. Mol. Cells 34, 501-507 (2012).
17. Zhou, L. L., Shi, M. Z. \& Xie, D. Y. Regulation of anthocyanin biosynthesis by nitrogen in TTG1-GL3/TT8-PAP1-programmed red cells of Arabidopsis thaliana. Planta 236, 825-837 (2012).

18. O'Brien, J. A. et al. Nitrate transport, sensing, and responses in plants. Mol. Plant 9, 837-856 (2016)

19. Fredes, I., Moreno, S., Diaz, F. P. \& Gutierrez, R. A. Nitrate signaling and the control of Arabidopsis growth and development. Curr. Opin. Plant Biol. 47, 112-118 (2019).

20. Lea, U. S., Slimestad, R., Smedvig, P. \& Lillo, C. Nitrogen deficiency enhances expression of specific MYB and bHLH transcription factors and accumulation of end products in the flavonoid pathway. Planta 225, 1245-1253 (2007).

21. Rubin, G., Tohge, T., Matsuda, F., Saito, K. \& Scheible, W. R. Members of the LBD family of transcription factors repress anthocyanin synthesis and affect additional nitrogen responses in Arabidopsis. Plant Cell 21, 3567-3584 (2009).

22. Peng, M., Hannam, C., Gu, H., Bi, Y. M. \& Rothstein, S. J. A mutation in NLA, which encodes a RING-type ubiquitin ligase, disrupts the adaptability of Arabidopsis to nitrogen limitation. Plant J. 50, 320-337 (2007).

23. Peng, M. et al. Adaptation of Arabidopsis to nitrogen limitation involves induction of anthocyanin synthesis which is controlled by the NLA gene. J. Exp. Bot. 59, 2933-2944 (2008).

24. Zhang, Y. et al. GA-DELLA pathway is involved in regulation of nitrogen deficiency-induced anthocyanin accumulation. Plant Cell Rep. 36, 557-569 (2017).

25. Wang, X. F. et al. The nitrate-responsive protein MdBT2 regulates anthocyanin biosynthesis by interacting with the MdMYB1 transcription factor. Plant Physiol. 178, 890-906 (2018).

26. Gingerich, D. J., Hanada, K., Shiu, S. H. \& Vierstra, R. D. Large-scale, lineagespecific expansion of a bric-a-brac/tramtrack/broad complex ubiquitin-ligase gene family in rice. Plant Cell 19, 2329-2348 (2007).

27. Araus, $V$. et al. Members of BTB gene family of scaffold proteins suppress nitrate uptake and nitrogen use efficiency. Plant Physiol. 171, 1523-1532 (2016).

28. Sato, T. et al. Direct transcriptional activation of BT genes by NLP transcription factors is a key component of the nitrate response in Arabidopsis.Biochem. Biophys. Res. Commun. 483, 380-386 (2017)

29. Du, L. \& Poovaiah, B. W. A novel family of $\mathrm{Ca}^{2+} /$ calmodulin-binding proteins involved in transcriptional regulation: interaction with fsh/Ring3 class transcription activators. Plant Mol. Biol. 54, 549-569 (2004).

30. Zhao, Q. et al. Ubiquitination-related MdBT scaffold proteins target a bHLH transcription factor for iron homeostasis. Plant Physiol. 172 1973-1988 (2016).

31. Ren, S., Mandadi, K. K., Boedeker, A. L., Rathore, K. S. \& McKnight, T. D. Regulation of telomerase in Arabidopsis by BT2, an apparent target of TELOMERASE ACTIVATOR1. Plant Cell 19, 23-31 (2007).

32. Mandadi, K. K., Misra, A., Ren, S. \& McKnight, T. D. BT2, a BTB protein, mediates multiple responses to nutrients, stresses, and hormones in Arabidopsis. Plant Physiol. 150, 1930-1939 (2009).

33. Robert, H. S. et al. Domain scaffold proteins perform a crucial function in Arabidopsis development. Plant J. 58, 109-121 (2009).

34. An, J. P. et al. R2R3-MYB transcription factor MdMYB23 is involved in the cold tolerance and proanthocyanidin accumulation in apple. Plant J. 96, 562-577 (2018).

35. An, J. P. et al. MdbHLH93, an apple activator regulating leaf senescence, is regulated by $\mathrm{ABA}$ and $\mathrm{MdBT} 2$ in antagonistic ways. N. Phytol. 222, 735-751 (2019).

36. An, J. P. et al. MdBBX22 regulates UV-B-induced anthocyanin biosynthesis through regulating the function of MdHY5 and is targeted by MdBT2 for $26 \mathrm{~S}$ proteasome-mediated degradation. Plant Biotechnol. J. 17, 2231-2233 (2019).

37. An, J. P. et al. MdWRKY40 promotes wounding-induced anthocyanin biosynthesis in association with MdMYB1 and undergoes MdBT2-mediated degradation. N. Phytol. 224, 380-395 (2019).

38. An, J. P. et al. Dynamic regulation of anthocyanin biosynthesis at different light intensities by the BT2-TCP46-MYB1 module in apple. J. Exp. Bot. 71, 3094-3109 (2020).

39. An, J. P. et al. The ERF transcription factor MdERF38 promotes drought stress induced anthocyanin biosynthesis in apple. Plant J. 101, 573-589 (2020).

40. Baena-Gonzalez, E. \& Sheen, J. Convergent energy and stress signaling. Trends Plant Sci. 13, 474-482 (2008).

41. Ren, Y. R. et al. MdGRF11, an apple 14-3-3 protein, acts as a positive regulator of drought and salt tolerance. Plant Sci. https://doi.org/10.1016/j. plantsci.2019.110219 (2019). 
42. Peretz, Y. et al. A universal expression/silencing vector in plants. Plant Physiol. 145, 1251-1263 (2007).

43. Ratcliff, F., Martinhernandez, A. M. \& Baulcombe, D. C. Technical advance. Tobacco rattle virus as a vector for analysis of gene function by silencing. Plant J. 25, 237-245 (2008).

44. Li, Y. Y. et al. MdCOP1 ubiquitin E3 ligases interact with MdMYB1 to regulate light-induced anthocyanin biosynthesis and red fruit coloration in apple. Plant Physiol. 160, 1011-1022 (2012).

45. Ma, Q. J. et al. An apple CIPK protein kinase targets a novel residue of AREB transcription factor for ABA-dependent phosphorylation. Plant Cell Environ. 40, 2207-2219 (2017)

46. An, X. H. et al. MdMYB9 and MdMYB11 are involved in the regulation of the JA-induced biosynthesis of anthocyanin and proanthocyanidin in apples. Plant Cell Physiol. 56, 650-662 (2015).

47. Walter, M. et al. Visualization of protein interactions in living plant cells using bimolecular fluorescence complementation. Plant J. 40, 428-438 (2004).

48. Liu, X. J. et al. An apple protein kinase MdSnRK1.1 interacts with MdCAIP1 to regulate ABA sensitivity. Plant Cell Physiol. 58, 1631-1641 (2017).

49. Ji, X. H. et al. Effect of auxin, cytokinin and nitrogen on anthocyanin biosynthesis in callus cultures of red-fleshed apple (Malus sieversii f.niedzwetzkyana). Plant Cell Tiss. Org. 120, 325-337 (2015).

50. Roberts, M. R. 14-3-3 proteins find new partners in plant cell signalling. Trends Plant Sci. 8, 218-223 (2003).

51. Dougherty, M. K. \& Morrison, D. K. Unlocking the code of 14-3-3. J. Cell Sci. 117, 1875-1884 (2004).

52. Figueroa, P. et al. Arabidopsis has two redundant Cullin3 proteins that are essential for embryo development and that interact with RBX1 and BTB proteins to form multisubunit E3 ubiquitin ligase complexes in vivo. Plant Cell 17, 1180-1195 (2005).

53. Li, J. J., Zhang, T. P., Meng, Y., Du, J. \& Li, H. H. Stability of F-box protein atrogin1 is regulated by p38 mitogen-activated protein kinase pathway in cardiac H9c2 cells. Cell Physiol. Biochem. 27, 463-470 (2011).

54. Wei, W. et al. Degradation of the SCF component Skp2 in cell-cycle phase G1 by the anaphase-promoting complex. Nature 428, 194-198 (2004).
55. Sepulveda-Garcia, E. \& Rocha-Sosa, M. The Arabidopsis F-box protein AtFBS1 interacts with 14-3-3 proteins. Plant Sci. 195, 36-47 (2012).

56. Denison, F. C., Paul, A. L., Zupanska, A. K. \& Ferl, R. J. 14-3-3 proteins in plant physiology. Semin. Cell Dev. Biol. 22, 720-727 (2011).

57. Paul, A. L., Denison, F. C., Schultz, E. R., Zupanska, A. K. \& Ferl, R. J. 14-3-3 phosphoprotein interaction networks-does isoform diversity present functional interaction specification? Front. Plant Sci. 3, 190 (2012).

58. Nabbie, F. et al. 14-3-3 Lambda protein affects anthocyanin production in Arabidopsis thaliana during drought stress. J. Agric. Sci. 9, 22 (2017).

59. Gould, K. S., Mckelvie, J. \& Markham, K. R. Do anthocyanins function as antioxidants in leaves? Imaging of $\mathrm{H}_{2} \mathrm{O}_{2}$ in red and green leaves after mechanical injury. Plant Cell Environ. 25, 1261-1269 (2002).

60. Yang, H. Y. et al. Roles for negative cell regulator 14-3-3 sigma in control of MDM2 activities. Oncogene 26, 7355-7362 (2007).

61. Su, C. H. et al. 14-3-3 sigma exerts tumor-suppressor activity mediated by regulation of COP1 stability. Cancer Res. 71, 884-894 (2011).

62. Yoon, G. M. \& Kieber, J. J. 14-3-3 regulates 1-aminocyclopropane-1-carboxylate synthase protein turnover in Arabidopsis. Plant Cell 25, 1016-1028 (2013).

63. Ho, M. S., Ou, C., Chan, Y. R., Chien, C. T. \& Pi, H. The utility F-box for protein destruction. Cell Mol. Life Sci. 65, 1977-2000 (2008).

64. Seibert, $V$. et al. Combinatorial diversity of fission yeast SCF ubiquitin ligases by homo- and heterooligomeric assemblies of the F-box proteins Pop1p and Pop2p. BMC Biochem. 3, 22 (2002).

65. Welcker, M. \& Clurman, B. E. Fbw7/hCDC4 dimerization regulates its substrate interactions. Cell Div. 2, 7 (2007).

66. Pintard, L. et al. The BTB protein MEL-26 is a substrate-specific adaptor of the CUL-3 ubiquitin-ligase. Nature 425, 311-316 (2003).

67. McMahon, M., Thomas, N., Itoh, K., Yamamoto, M. \& Hayes, J. D. Dimerization of substrate adaptors can facilitate cullin-mediated ubiquitylation of proteins by a "tethering" mechanism: a two-site interaction model for the Nrf2-Keap1 complex. J. Biol. Chem. 281, 24756-24768 (2006).

68. Barbash, O., Lee, E. K. \& Diehl, J. A. Phosphorylation-dependent regulation of $\mathrm{SCF}^{\mathrm{Fb} \times 4}$ dimerization and activity involves a novel component, 14-3-3 epsilon. Oncogene 30, 1995-2002 (2011). 